\title{
Increased YKL-40 and Chitotriosidase in Asthma and Chronic Obstructive Pulmonary Disease
}

\begin{abstract}
Anna J. James ${ }^{1,2}$, Lovisa E. Reinius ${ }^{2,3,4}$, Marri Verhoek ${ }^{5}$, Anna Gomes ${ }^{1,2}$, Maciej Kupczyk ${ }^{1,2}$, Ulf Hammar ${ }^{1}$, Junya Ono ${ }^{6}$, Shoichiro Ohta ${ }^{7}$, Kenji Izuhara ${ }^{8}$, Elisabeth Bel ${ }^{9}$, Juha Kere ${ }^{2,3,4}$, Cilla Söderhäll ${ }^{2,3,4}$, Barbro Dahlén ${ }^{2,10}$, Rolf G. Boot ${ }^{5}$, and Sven-Erik Dahlén ${ }^{1,2}$; on behalf of the BIOAIR (Longitudinal Assessment of Clinical Course and Biomarkers in Severe Chronic Airway Disease) Consortium*

${ }^{1}$ Institute of Environmental Medicine, ${ }^{2}$ Center for Allergy Research, ${ }^{3}$ Center for Innovative Medicine, and ${ }^{4}$ Department of Biosciences and Nutrition, Karolinska Institutet, Stockholm, Sweden; ${ }^{5}$ Department of Biochemistry, Leiden Institute of Chemistry, Leiden University, Leiden, the Netherlands; ${ }^{6}$ Shino-Test Corporation, Sagamihara, Japan; ${ }^{7}$ Department of Laboratory Medicine and ${ }^{8}$ Division of Medical Biochemistry, Department of Biomolecular Sciences, Saga Medical School, Saga University, Saga, Japan; ${ }^{9}$ Department of Pulmonology, Academic Medical Center, University of Amsterdam, Amsterdam, the Netherlands; and ${ }^{10}$ Department of Medicine, Karolinska University Hospital, Huddinge, Stockholm, Sweden
\end{abstract}

\begin{abstract}
Rationale: Serum chitinases may be novel biomarkers of airway inflammation and remodeling, but less is known about factors regulating their levels.
\end{abstract}

Objectives: To examine serum chitotriosidase activity and YKL-40 levels in patients with asthma and chronic obstructive pulmonary disease (COPD) and evaluate clinically relevant factors that may affect chitinase levels, including genetic variability, corticosteroid treatment, disease exacerbations, and allergen exposure.

Methods: Serum chitotriosidase (CHIT1) activity and YKL-40 (CHI3L1) levels, as well as the CHIT1 rs3831317 and CHI3L1 rs4950928 genotypes, were examined in subsets of patients with mild to moderate asthma $(n=76)$, severe asthma $(n=93)$, and COPD $(n=64)$ taking part in the European multicenter BIOAIR (Longitudinal Assessment of Clinical Course and Biomarkers in Severe Chronic Airway Disease) study. Blood was obtained at baseline, before and after a 2 -week oral steroid intervention, up to six times during a 1-year period, and during exacerbations. Baseline chitinase levels were also measured in 72 healthy control subjects. The effect of allergen inhalation on blood and sputum YKL-40 levels was measured in two separate groups of patients with mild atopic asthma; one group underwent repeated low-dose allergen challenge $(n=15)$, and the other underwent high-dose allergen challenge $(n=16)$.

Measurements and Main Results: Serum chitotriosidase and YKL40 were significantly elevated in patients with asthma and those with COPD compared with healthy control subjects. Genotype and age strongly affected both YKL-40 and chitotriosidase activity, but associations with disease remained following adjustment for these factors. Correlations were observed with lung function but not with other biomarkers, including exhaled nitric oxide, blood eosinophils, periostin, and IgE. Generally, acute exacerbations, allergen-induced airway obstruction, and corticosteroid treatment did not affect circulating chitinase levels.

Conclusions: YKL-40 and chitotriosidase are increased in asthma and more so in COPD. The data in the present study support these substances as being relatively steroid-insensitive, non-T-helper cell type 2-type biomarkers distinctly related to chronic inflammatory disease processes.

Keywords: asthma; chitotriosidase; chronic obstructive pulmonary disease; YKL-40

(Received in original form April 16, 2015; accepted in final form September 15, 2015)

${ }^{*}$ A complete list of members may be found before the beginning of the REFERENCES.

The following Swedish research funding bodies provided financial support: the Medical Research Council, the Heart-Lung Foundation, the Vårdal Foundation, the Stockholm County Council (ALF), the Swedish Asthma and Allergy Association, the Swedish Foundation for Strategic Research, Konsul Th C Berghs Foundation, the Karolinska Institutet SciLifeLab collaborations on translational medicine (ChAMP project), the Innovative Medicines Initiative project U-BIOPRED (unbiased biomarkers for the prediction of respiratory disease outcomes), and Karolinska Institutet.

Author Contributions: A.J.J. performed experimental analyses and data analysis and wrote the manuscript together with S.-E.D.; L.E.R., M.V., and A.G. performed experimental analyses and interpreted data; M.K. analyzed subject characteristics; U.H. performed statistical analyses; J.O., S.O., and K.I. developed and performed periostin measurements; C.S. and J.K. were responsible for genetic analyses; R.G.B. devised and was responsible for chitinase activity measurements; and E.B., B.D., and S.-E.D. conceived of and designed the study. The clinical investigators of the BIOAIR consortium (listed as collaborators before the beginning of the REFERENCES) developed the overall study protocol and enrolled the patients to create this cohort. All authors participated in drafting the manuscript, revised it critically for content, and approved its submission.

Correspondence and requests for reprints should be addressed to Anna J. James, Ph.D., Institute of Environmental Medicine, Karolinska Institutet, P.O. Box 287, 17177 Stockholm, Sweden. E-mail: anna.james@ki.se

This article has an online supplement, which is accessible from this issue's table of contents at www.atsjournals.org

Am J Respir Crit Care Med Vol 193, Iss 2, pp 131-142, Jan 15, 2016

Copyright $\odot 2016$ by the American Thoracic Society

Originally Published in Press as DOI: 10.1164/rccm.201504-07600C on September 16, 2015

Internet address: www.atsjournals.org 


\section{At a Glance Commentary}

\section{Scientific Knowledge on the}

Subject: The chitinases and related proteins have shown promise as novel circulating markers of inflammation in patients with respiratory disease.

\section{What This Study Adds to the}

Field: We contribute knowledge to this field regarding factors that regulate levels of chitinases and related proteins in the blood. We conclude that these proteins are relatively steroidinsensitive, non-T-helper cell type 2specific markers of chronic rather than acute disease processes.

To realize the concept of precision medicine in patients with severe airway inflammation, who are notoriously difficult to treat, there is a great need for novel biomarkers of this disease. A relatively unexpected group of proteins has been proposed to show potential for this purpose-the chitinases.

Chitin is an abundant, tough structural polysaccharide used by a variety of organisms, including insects, crustaceans, parasites, fungi, and bacteria, to protect against external threats (1). Although in humans chitin seems absent, enzymes capable of its degradation are expressed. The chitinase family includes the true chitinases-acidic mammalian chitinase (AMCase) and chitotriosidase-as well as the structurally related chitinase-like protein YKL-40, which lacks enzymatic activity (2). In recent years, these proteins have been linked to airway inflammation (2). Although AMCase has been associated with airway inflammation predominantly in animal models (3), chitotriosidase activity is increased in the airways of smokers and subjects with chronic obstructive pulmonary disease (COPD) compared with healthy control subjects $(4,5)$, as well as in the serum of patients with asthma (6). YKL-40 levels are increased in the serum and lungs of patients with asthma compared with healthy control subjects, and they correlate with markers of disease severity $(7,8)$.

However, information is still lacking regarding the suitability of these proteins as biomarkers of airway inflammation. It was therefore our aim in this study to provide a more detailed evaluation of serum chitinase levels in airway disease by investigating both serum YKL-40 levels and chitotriosidase activity in parallel in patients taking part in the European multicenter BIOAIR (Longitudinal Assessment of Clinical Course and Biomarkers in Severe Chronic Airway Disease) study (9-11). The design of this study enabled us, for the first time, to examine in the same study the repeatability of chitinase measurements over a 1-year period, the effect of oral steroid treatment, and the effect of spontaneous exacerbations in both patients with asthma and patients with COPD. YKL-40 levels and chitotriosidase activity are subject to genetic regulation and were therefore also analyzed, taking into account the effect of common polymorphisms in the CHI3L1 and CHIT1 genes, respectively. CHI3L1 rs4950928 $(-131 \mathrm{C}>\mathrm{G})$ has been associated with features of asthma and increased serum YKL-40 $(8,12)$, and individuals homozygous for a relatively common 24-bp duplication in exon 10 of CHIT1 (rs3831317) display a complete lack of chitotriosidase activity (13). To assess whether acute airway obstruction and inflammation affect chitinase levels in blood or sputum, we also examined the effect of inhaled allergen on YKL-40 levels in two separate subsets of patients with mild atopic asthma following high-dose or repeated lowdose allergen challenge. Some of the results of these studies have been reported previously in the form of abstracts (14-16).

\section{Methods}

\section{Subjects}

BIOAIR cohort. BIOAIR is a European multicenter study (9-11). Briefly, subjects were between 18 and 80 years of age and were divided into three groups: patients with mild to moderate asthma, patients with severe asthma, and patients with COPD (Table 1). Further details and definitions regarding the BIOAIR study and patient groups are provided in the online supplement. To examine the repeatability of biomarker measurements, patients attended up to six scheduled clinic visits over the 1-year study period. Patients who had exacerbations had additional visits. Most patients taking part in the BIOAIR study ( $88 \%$ of all subjects) underwent a 2-week, double-blind, placebo-controlled oral steroid intervention consisting of a standard course of prednisolone $(0.5 \mathrm{mg} / \mathrm{kg}$ body weight/d) added to regular treatment. For certain comparisons, a positive response to therapy was defined as an increase in $\mathrm{FEV}_{1}$ greater than $12 \%$ following steroid treatment.

Healthy subjects. Baseline chitinase measurements were obtained from a group of up to 72 healthy volunteers aged 21-77 years (average age, $40 \mathrm{yr}$ ) recruited at the Academic Medical Center, University of Amsterdam, who have been examined in previous studies of chitinase levels (17).

\section{Allergen-challenged subjects with} asthma. Plasma and sputum samples were collected from well-characterized patients with mild atopic asthma taking part in two separate allergen challenge studies (see online supplement for details). Patients underwent either (1) high-dose allergen challenge $(n=16)$ to produce a $20 \%$ acute fall in $\operatorname{FEV}_{1}$ (18) or (2) repeated low-dose allergen challenge $(n=15)$ leading to minimal bronchoconstriction but eosinophilic airway inflammation and increased bronchial hyperresponsiveness to methacholine (19).

\section{Clinical Measurements}

Lung function measurements, reversibility testing, fraction of exhaled nitric oxide $\left(\mathrm{FE}_{\mathrm{NO}}\right)$ measurements, skin prick testing, and sputum induction and processing were all performed as described in the online supplement. Serum periostin levels were measured by ELISA using two rat antihuman periostin monoclonal antibodies (clones SS18A and SS17B) as described previously (20).

YKL-40 assay. Serum YKL-40 levels were measured by ELISA according to the manufacturer's instructions (Human Chitinase 3-like 1 DuoSet ELISA Development Kit; R\&D Systems, Abingdon, UK). Two different dilutions were made for each sample, from which an average was obtained. All samples were analyzed in duplicate in random order. Within-assay variability was $3 \%$, and between-assay variability was $14 \%$.

Chitotriosidase assay. Chitotriosidase activity in the serum was detected fluorometrically using the substrate 4-methylumbelliferyl-(4-deoxy)chitobiose as described elsewhere $(21,22)$ and as outlined in more detail in the online supplement. To discriminate between chitotriosidase activity and that of AMCase in serum samples, a neutralizing antibody against AMCase was used. 
Table 1. Baseline Subject Characteristics (BIOAIR Study)

\begin{tabular}{|c|c|c|c|c|}
\hline & $\begin{array}{l}\text { Mild to Moderate } \\
\text { Asthma }\end{array}$ & Severe Asthma & COPD & $P$ Value \\
\hline Total number of patients included & 76 & 93 & 64 & ND \\
\hline Age, yr, mean \pm SD (min-max) & $43.4 \pm 1.6(21-70)$ & $50.2 \pm 1.4(18-72)$ & $64.3 \pm 1.1(47-79)$ & $<0.0001^{*}$ \\
\hline Females, \% & 59.7 & 57.1 & 22.6 & $<0.0001^{\dagger}$ \\
\hline $\mathrm{FEV}_{1}, \%$ predicted & $89.9 \pm 2.5$ & $73.2 \pm 2.3$ & $48.04 \pm 1.9$ & $<0.0001^{\star}$ \\
\hline $\mathrm{FEV}_{1}, \mathrm{~L}$ & $2.76 \pm 0.09$ & $2.08 \pm 0.08$ & $1.40 \pm 0.08$ & $<0.0001^{\star}$ \\
\hline $\mathrm{FEV}_{1} / \mathrm{FVC}$ & $0.70 \pm 0.01$ & $0.67 \pm 0.01$ & $0.51 \pm 0.01$ & $<0.0001^{\dagger}$ \\
\hline Reversibility, $\Delta \mathrm{FEV}_{1} \%$ predicted & $10.5 \pm 0.7$ & $8.7 \pm 0.7$ & $3.4 \pm 0.5$ & $<0.0001^{\dagger}$ \\
\hline $\begin{array}{l}\text { ICS (beclomethasone equivalent), } \mu \mathrm{g} \text {, } \\
\text { median (mean } \pm \mathrm{SD} \text { ) }\end{array}$ & $775(606 \pm 223)$ & $1,600(2,044 \pm 912)$ & $800(1,062 \pm 631)$ & $<0.0001^{\dagger}$ \\
\hline $\begin{array}{l}\text { OCS (prednisolone equivalent), }{ }^{\ddagger} \text { mg, } \\
\text { median (mean } \pm \text { SD) }\end{array}$ & - & $10(14.15 \pm 11.8)$ & & ND \\
\hline $\mathrm{BMI}, \mathrm{kg} / \mathrm{m}^{2}$ & $25.2 \pm 0.5$ & $28.3 \pm 0.6$ & $27.3 \pm 0.7$ & $0.0004^{\S}$ \\
\hline $\begin{array}{l}\text { St. George's Respiratory Questionnaire } \\
\text { score }\end{array}$ & $23.2 \pm 2.2$ & $44.8 \pm 2.1$ & $44.5 \pm 2.3$ & $<0.0001^{\S}$ \\
\hline Asthma Control Questionnaire score & $1.03 \pm 0.7$ & $2.03 \pm 0.1$ & - & $<0.0001^{\|}$ \\
\hline $\mathrm{CRP}, \mathrm{mg} / \mathrm{L}$ & $4.6 \pm 1.2$ & $5.6 \pm 0.8$ & $10.4 \pm 2.2$ & $0.01^{\dagger}$ \\
\hline Atopy, \% & 46.9 & 37.6 & - & $1.0^{\star \star}$ \\
\hline $\mathrm{F}_{\mathrm{E}_{\mathrm{NO}}, \mathrm{ppb}}$ & $39.3 \pm 4.4$ & $46.9 \pm 6.6$ & $17.0 \pm 2.9$ & $0.002^{*}$ \\
\hline Serum periostin, ng/ml & $86.0 \pm 25.75$ & $93.5 \pm 45.21$ & $80.1 \pm 24.02$ & $0.05^{\dagger}$ \\
\hline Sputum eosinophils, \% & $5.9 \pm 1.8$ & $17.9 \pm 3.7$ & $3.3 \pm 1.7$ & $0.001^{*}$ \\
\hline Sputum neutrophils, \% & $45.8 \pm 4.4$ & $40.4 \pm 3.8$ & $62.7 \pm 5.1$ & $0.004^{\dagger}$ \\
\hline Blood eosinophils, $10^{8} / \mathrm{L}$ & $3.20 \pm 0.4$ & $3.75 \pm 0.4$ & $2.72 \pm 0.4$ & 0.22 \\
\hline Blood neutrophils, $10^{9} / \mathrm{L}$ & $3.78 \pm 0.15$ & $5.43 \pm 0.29$ & $5.03 \pm 0.23$ & $<0.0001^{\mathrm{s}}$ \\
\hline
\end{tabular}

Definition of abbreviations: BIOAIR = Longitudinal Assessment of Clinical Course and Biomarkers in Severe Chronic Airway Disease; BMI = body mass index; $\mathrm{COPD}=$ chronic obstructive pulmonary disease; $\mathrm{CRP}=\mathrm{C}$-reactive protein; $\mathrm{F}_{\mathrm{NO}}=$ fraction of exhaled nitric oxide; ICS = inhaled corticosteroids; $\mathrm{ND}=$ not determined; OCS $=$ oral corticosteroids

Data are mean \pm SD unless otherwise noted.

*Three-way comparison significant; all groups are different.

†Significant difference between patients with severe asthma and those with COPD.

${ }^{\ddagger}$ One patient with COPD received $60 \mathrm{mg} / \mathrm{d}$ of prednisolone.

\$Significant difference between patients with severe and those with mild to moderate asthma.

"Mann-Whitney $U$ test.

"Atopy was an exclusion criterion for the COPD group.

${ }^{* *} \chi^{2}$ test.

\section{Genotyping}

The CHIT1 24-bp duplication (rs3831317) and $-131 \mathrm{C}>\mathrm{G}$ polymorphism in the CHI3L1 gene (rs4950928) were genotyped as described in the online supplement. DNA was available from subjects taking part in the BIOAIR study ( $\mathrm{n}=179$ ), as well as from the healthy control subjects $(\mathrm{n}=58$ for CHI3L1 and $\mathrm{n}=72$ for CHIT1).

\section{Statistics}

Basic comparisons were performed using GraphPad Prism statistical software (GraphPad Software, La Jolla, CA), and $P$ values $<0.05$ were accepted as significant. The majority of variables in this study were not normally distributed according to the Kolmogorov-Smirnov test and therefore were analyzed using nonparametric tests. The results are presented as median (interquartile range) unless otherwise stated. Further analyses were performed using Stata 13 software (StataCorp, College
Station, TX). Linear regression was used to adjust for age, sex, and genotype, and a linear mixed model was used for dependent samples (e.g., before vs. after treatment). For all regression analyses, logarithmic transformations of chitinase and YKL-40 measurements were performed before analysis. Fisher's exact test was used to examine genotype frequencies between groups. Multiple regression models were constructed to examine the effects of age, sex, genotype, smoking, disease, and lung function on chitinase levels. Some variables showed clear deviations from linearity, and these were fitted using cubic splines with three knots (23).

\section{Results}

\section{Baseline Serum YKL-40 Levels and Chitotriosidase Activity}

The results are presented as median (interquartile range). Compared with serum
YKL-40 levels in healthy control subjects $(23.0$ [17.1-26.5] ng/ml; $\mathrm{n}=48)$, levels were significantly elevated in patients with mild to moderate asthma (33.3 [22.9-43.5] ng/ml; $\mathrm{n}=61 ; P<0.001)$ and those with severe asthma (43.3 [31.1-75.9] ng/ml; $\mathrm{n}=76$; $P<0.001)$ and were highest in patients with COPD (64.0 [37.4-142.2] ng/ml; $\mathrm{n}=45 ; P<0.001$ ) (Figure 1A). All patient groups were significantly different compared with each other (mild to moderate asthma vs. severe asthma, $P=0.002$; mild to moderate asthma vs. COPD, $P<0.001$; severe asthma vs. COPD, $P=0.006)$.

Compared with healthy control subjects $(62.5[46.0-90.0] \mathrm{nmol} / \mathrm{ml} / \mathrm{h}$; $\mathrm{n}=72$ ), serum chitotriosidase activity was greatest in patients with COPD $(169.5$ $[90.0-269.6] \mathrm{nmol} / \mathrm{ml} / \mathrm{h} ; \mathrm{n}=52 ; P<0.001)$ but was also significantly elevated in subjects with mild to moderate asthma (96.3 [61.3-137.6] nmol/ml/h; $\mathrm{n}=63 ; P<$ 
A

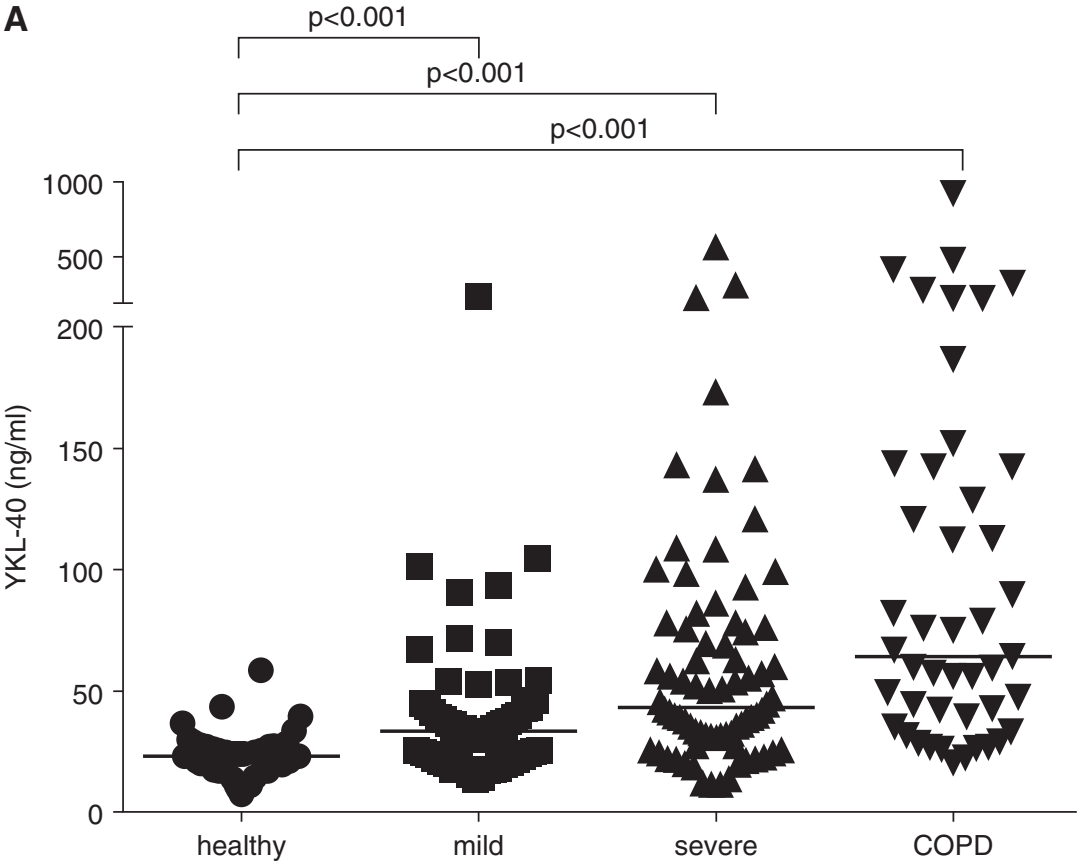

B

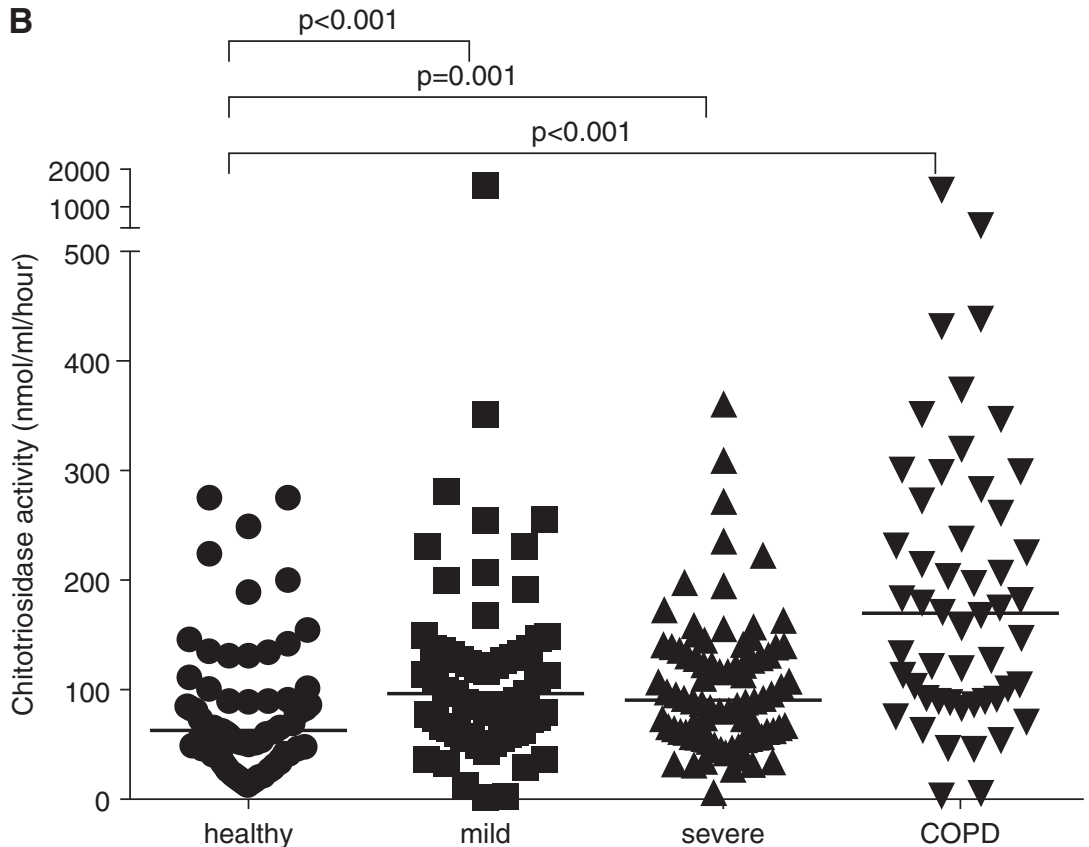

Figure 1. Serum levels of $Y K L-40$ and chitotriosidase activity. (A) YKL-40 levels are shown in healthy control subjects and patients with mild to moderate or severe asthma and patients with chronic obstructive pulmonary disease (COPD). (B) Chitotriosidase activity is shown in healthy control subjects, patients with mild to moderate or severe asthma, and patients with COPD. $P$ values are shown for comparisons with healthy control subjects. The results are presented as individual data points with median bars.

$0.001)$ and those with severe asthma $(90.7$ [58.1-134.8] nmol $/ \mathrm{ml} / \mathrm{h} ; \mathrm{n}=84 ; P=0.001)$ (Figure 1B). Chitotriosidase levels in both asthma groups were lower than those in patients with COPD $(P<0.001)$. subject groups are shown in Table 2. The occurrence of the different genotypes was not different between the subject groups $(P=0.976$ for CHI3L1 rs4950928 and $P=0.421$ for CHIT1 rs3831317).

YKL-40 levels were related to $C H I 3 L 1$ rs4950928 genotype (Figure 2A). When all subjects were analyzed together, those with the CC genotype showed higher levels of serum YKL-40 (39.0 [25.5-75.5] ng/ml; $\mathrm{n}=120)$ than those with the CG genotype (32.2 [20.2-47.5] ng/ml; $\mathrm{n}=54 ; P=0.009$ ) and those with the GG genotype, in whom levels were lowest $(18.1[11.5-28.3] \mathrm{ng} / \mathrm{ml}$; $\mathrm{n}=11 ; P<0.001)$.

Following regression analyses with adjustment for CHI3L1 rs4950928 genotype, age, and sex, patients with mild and severe asthma and patients with COPD all still had significantly higher YKL-40 levels than healthy control subjects $(P<$ 0.001). A significant difference also remained between patients with mild asthma and those with COPD $(P=0.018)$, but not between patients with mild asthma and those with severe asthma $(P=0.062)$ or between patients with severe asthma and those with COPD $(P=0.283)$.

Serum chitotriosidase activity showed a strong relationship with CHIT1 rs3831317 genotype (Figure 2B). Subjects homozygous for a 24-bp duplication in exon 10 were completely lacking in chitotriosidase activity, although this genotype was rare among subjects ( $2.3 \%$ in total) and therefore the data were too few to be included in statistical comparisons. Comparing all subjects, those lacking the 24-bp duplication had significantly greater levels of chitotriosidase than heterozygotes (respectively, 113.6 [74.5-156.6] [ $\mathrm{n}=146]$ vs. $59.2[36.0-86.2] \mathrm{nmol} / \mathrm{ml} / \mathrm{h}$ $[\mathrm{n}=76] ; P<0.0001)$.

When between-group differences in chitotriosidase activity were examined in regression analyses with adjustment for age, sex, and genotype, mild asthma and COPD were significantly different compared with healthy control subjects $(P<0.001)$, whereas severe asthma was not $(P=0.106)$. There were also significant differences in chitotriosidase activity between COPD and severe asthma $(P=0.007)$ and between mild and severe asthma $(P=0.051)$, but not between mild asthma and COPD $(P=0.416)$.

Overall, there were no associations between CHI3L1 rs4950928 or CHIT1 rs3831317 genotype and subject characteristics (see Tables E4 and E5 in the 
Table 2. Frequencies of CHI3L1 rs4950928 and CHIT1 rs3831317 Genotypes

\begin{tabular}{lccc}
\hline CHI3L1 rs4950928 & CC & CG & GG \\
Mild to moderate asthma $(n=49)$ & 61.2 & 30.6 & 8.2 \\
Severe asthma $(n=62)$ & 63.0 & 30.6 & 6.4 \\
COPD $(n=40)$ & 67.5 & 27.5 & 5.3 \\
Healthy control subjects $(n=57)$ & 70.2 & 24.5 & \\
& & & \\
& & & \\
CHIT1 rs3831317 & No 24-bp & Heterozygous & Homozygous \\
& Duplication & 31.0 & 3.5 \\
Mild to moderate asthma $(n=58)$ & 65.5 & 34.7 & 1.4 \\
Severe asthma $(n=72)$ & 63.9 & 28.6 & 4.1 \\
COPD ( $=49)$ & 67.3 & 39.1 & 0 \\
Healthy control subjects $(n=64)$ & 60.9 & & \\
\hline
\end{tabular}

Definition of abbreviation: COPD = chronic obstructive pulmonary disease.

Results are presented as percentages.

online supplement), apart from lower periostin levels in patients with asthma with the rs4950928 GG genotype (CC $=88$ [71-109] ng/ml; CG = 83 [67.8-102.3] ng/ml; $\mathrm{GG}=57.5[50.3-68.8] \mathrm{ng} / \mathrm{ml} ; P=0.003)$ and a higher body mass index (BMI) in patients with asthma lacking the 24-bp duplication at rs3831317, or wild type, compared to those heterozygous for the duplication (wild type $=$ $27[24-30] \mathrm{kg} / \mathrm{m}^{2}$; heterozygous = 26 [23-27] $\left.\mathrm{kg} / \mathrm{m}^{2} ; P=0.034\right)$. However, it should also be noted that the present study is underpowered to examine clinical characteristics between different genotypes in the resulting subgroups.

\section{Relationships between the Chitinases and Subject Characteristics}

Possible correlations between levels of serum YKL-40 and chitotriosidase activity and subject characteristics were examined (Table 3). In all BIOAIR patients, age was found to correlate positively with both YKL-40 $(r=0.49 ; P<0.001)$ and chitotriosidase activity $(r=0.47 ; P<0.001)$. Measures of lung function showed negative correlations with both YKL-40 levels (FEV $1 \%$ predicted, $r=-0.42, P<0.0001$; FVC $\%$ predicted, $r=-0.40, P<0.0001$; $\left.\mathrm{FEV}_{1} / \mathrm{FVC}, r=-0.34, P<0.001\right)$ and chitotriosidase levels $\left(\mathrm{FEV}_{1}, r=-0.25, P<\right.$ 0.001 ; FVC, $r=-0.16, P=0.03$; $\mathrm{FEV}_{1} / \mathrm{FVC}$, $r=-0.23, P=0.001)$. In addition, there was a weak but statistically significant correlation between serum YKL-40 level and

chitotriosidase activity $(r=0.221 ; P=0.003)$. Correlations in the separate subject groups are shown in Tables E6 and E7. YKL-40 also showed a weak though significant association with BMI, but only in patients with asthma ( $r=0.21 ; P=0.01)$.

\section{Chitinase Levels in T-Helper Cell Type 2-driven Asthma}

In patients with asthma, no significant correlations were observed between either YKL-40 level or chitotriosidase activity and proposed markers of T-helper cell type 2 (Th2)-type inflammation, including serum periostin, blood eosinophils, $\mathrm{FE}_{\mathrm{NO}}$, and total IgE (Table E6). To further examine possible relationships between chitinase levels and Th2-type inflammation, patients with asthma were divided into a Th2-high group, based on the presence of both blood eosinophil counts and periostin levels above the group median (median eosinophil count, $0.25 \times 10^{9} / \mathrm{L}$; median periostin level, $84 \mathrm{ng} / \mathrm{ml}$ ), and a Th2-low group, in whom levels of both biomarkers were below the median (Table 4). No differences in chitinase levels were observed between the Th2-low and Th2-high groups.

\section{Effect of Steroid Treatment on Chitinase Levels}

The effect of a 2-week, placebo-controlled oral steroid intervention was examined in subjects taking part in the BIOAIR study. No significant reductions in YKL-40 levels were observed following corticosteroid treatment (Figure 3A).

When the effect of steroid treatment was analyzed in all patient groups, serum chitotriosidase activity was slightly reduced following treatment with oral prednisolone (106 [66-168] vs. 101 [63-143] nmol/ml/h; $\mathrm{n}=157 ; \mathrm{P}<0.001)$. However, when patient groups were analyzed separately

(Figure 3B), oral steroid treatment caused a reduction in chitotriosidase activity only in patients with COPD (186 [111-279] vs. 128 (86-189) $\mathrm{nmol} / \mathrm{ml} / \mathrm{h} ; \mathrm{n}=38 ; P<0.001)$. When interactions between treatment and age were taken into account, the interaction between treatment and subject groups ceased to be significant. The interaction between treatment and age in this model was negative $(P=0.001)$; that is, the reduction in chitotriosidase activity was greater in older people. There were no interactions between the examined genotypes and effect of corticosteroid therapy on chitinase levels.

In patients with asthma, neither baseline YKL-40 level nor chitotriosidase activity was associated with response to corticosteroid therapy, defined as an increase in $\mathrm{FEV}_{1}$ greater than $12 \%$ following treatment with oral prednisolone. YKL-40 levels in nonresponders were 39 (26-69) $\mathrm{ng} / \mathrm{ml}(\mathrm{n}=102)$ compared with $33(25-53)$ $\mathrm{ng} / \mathrm{ml}$ in responders $(\mathrm{n}=22)(P=0.276)$, whereas chitotriosidase activity was 94 (61-132) $\mathrm{nmol} / \mathrm{ml} / \mathrm{h}$ in nonresponders compared with $94(60-158) \mathrm{nmol} / \mathrm{ml} / \mathrm{h}$ in responders $(P=0.594)$.

\section{Effect of Exacerbations on Chitinase Levels}

Compared with baseline, neither YKL-40 level nor chitotriosidase activity was significantly different during exacerbations (Table E8). Exacerbations occurred in 7 patients with mild to moderate asthma, 27 patients with severe asthma, and 11 patients with COPD. Chitinase levels before and during exacerbations showed no significant interactions with age or genotype.

\section{Repeatability of Chitinase Measurements}

In the BIOAIR study, patients were followed for 1 year, during which time up to six blood samples were obtained at different time points (not during exacerbations). The data for average between-visit variability for YKL-40 levels and serum chitotriosidase activity, as well as the variability of $\mathrm{FE}_{\mathrm{NO}}$ and percentage of sputum eosinophils for comparison, are shown in Table 5.

\section{Chitinase Levels and Smoking Status}

Of 76 patients with mild asthma, 1 was a current smoker and 14 were former smokers. Of 93 patients with severe asthma, 29 were former smokers and 2 were current 
A

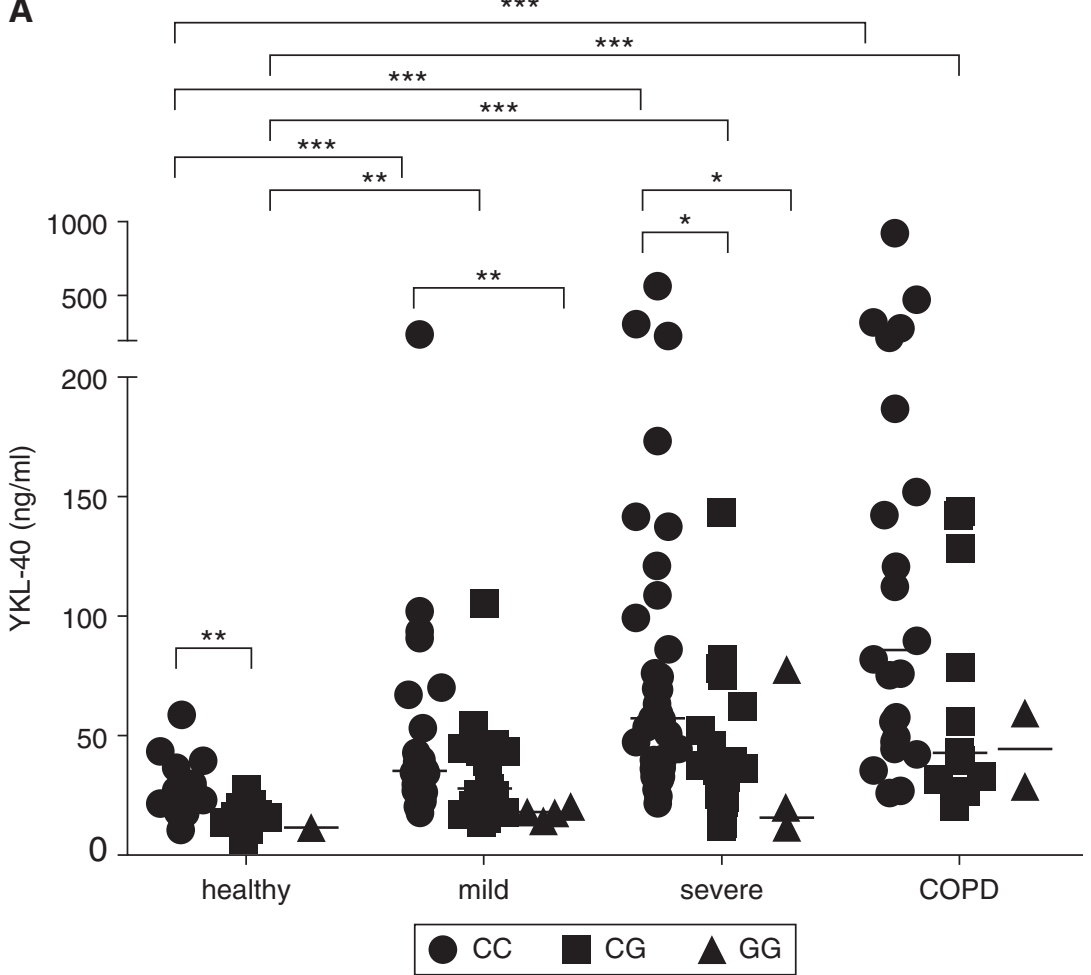

B

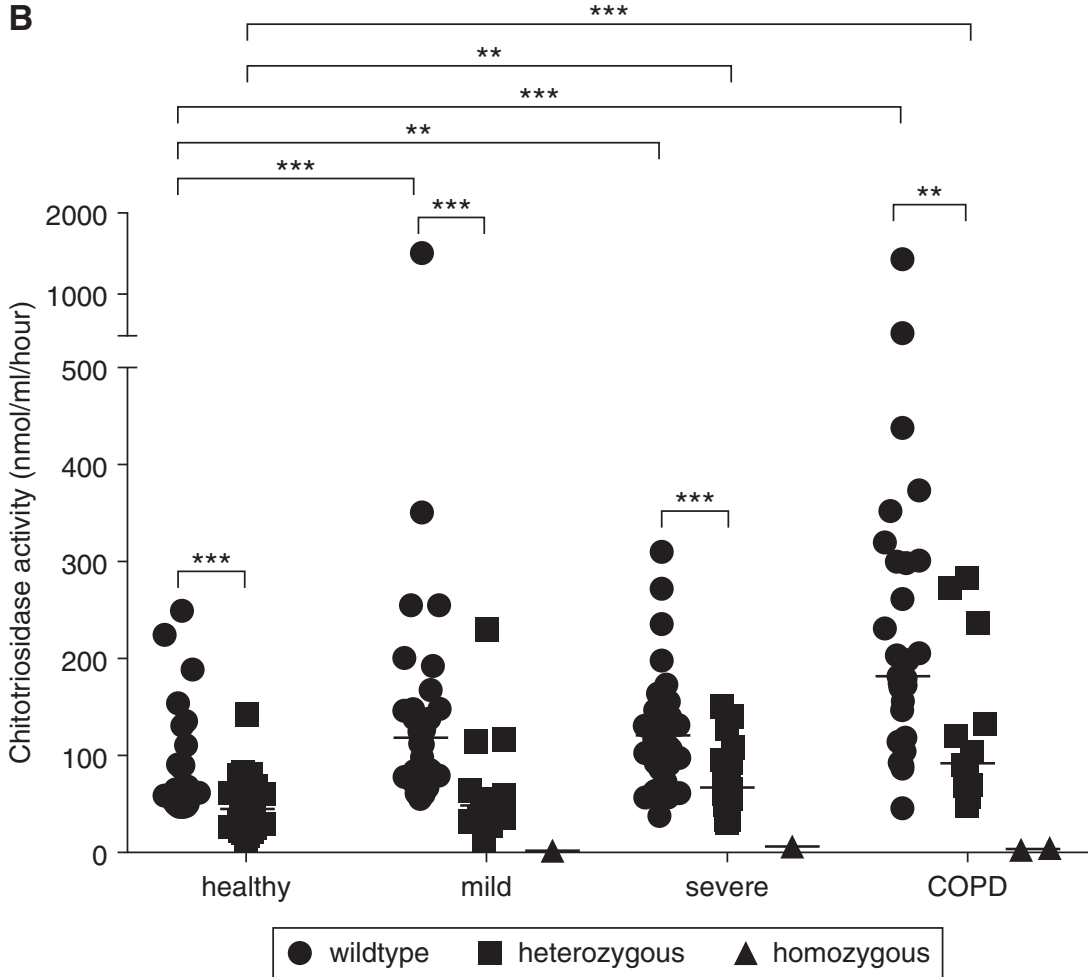

Figure 2. Serum levels of YKL-40 and chitotriosidase activity according to CHI3L1 rs4950928 and CHIT1 rs3831317 genotype. (A) YKL-40 levels and (B) chitotriosidase activity are shown in the different subject groups according to relevant genotype. YKL-40 is shown in subjects with the rs4950928 -131 CC, CG, and GG genotypes. Information regarding CHI3L1 genotype and YKL-40 levels was available for 39 healthy control subjects and 49 subjects with mild to moderate asthma, 60 with severe asthma, and 37 with chronic obstructive pulmonary disease (COPD). Chitotriosidase activity is shown in subjects lacking a 24-bp smokers. All 64 patients with COPD were either former $(n=45)$ or current $(n=19)$ smokers. We found no significant differences in either YKL-40 or chitotriosidase levels when we compared the patients with asthma who were never smokers with those who had smoked previously, nor did we find such differences when we compared patients with COPD who were former versus current smokers (Figure E2). When univariate correlations were performed on the BIOAIR group as a whole, a significant relationship with number of pack-years smoked was observed (Table 3), although this association was not apparent when the disease groups were analyzed separately (Tables E6 and E7).

\section{Multiple Regression Analyses}

As the findings above implied that YKL-40 levels and chitotriosidase activity are affected by several factors, we performed multiple regression analyses to examine the effects of the independent variables age, sex, genotype, smoking status, disease group, and lung function on chitinase levels.

In the BIOAIR patient group as a whole, YKL-40 levels were significantly associated with, in descending order of importance, lung function (FVC \% predicted), rs4950928 genotype, age, and sex (Tables 6 and 7). FVC showed a nonlinear relationship with YKL-40 levels, as demonstrated in Figure E3. For the whole patient group model, smoking (in packyears) and disease group were without significant effects. Multiple regression analyses in the separate groups are shown in Tables E9-E11. Generally similar associations were observed when the groups were analyzed separately, although there was no effect of lung function in patients with mild asthma (Table E9).

In descending order of importance in the BIOAIR group as a whole, genotype, age, and smoking status (in pack-years) were found to have significant effects on chitotriosidase activity. The difference between mild asthma and COPD was significant, but the difference between mild and severe asthma was not. No significant relationships with lung function were observed (Tables 6 and 7). The relationship between chitotriosidase activity and number of pack-years of smoking was not linear, as shown in Figure E4. When the patient groups were 
Table 3. Correlations between Subject Characteristics and Chitinase Levels in BIOAIR Subjects

\begin{tabular}{|c|c|c|c|c|}
\hline \multirow[b]{2}{*}{ Subject Characteristic } & \multicolumn{2}{|l|}{ YKL-40 (ng/mI) } & \multicolumn{2}{|c|}{ Chitotriosidase Activity $(\mathrm{nmol} / \mathrm{ml} / \mathrm{h})$} \\
\hline & $\begin{array}{c}\text { Spearman's Rank Correlation } \\
\text { Coefficient }\end{array}$ & $P$ Value & $\begin{array}{c}\text { Spearman's Rank Correlation } \\
\text { Coefficient }\end{array}$ & $P$ Value \\
\hline Age, yr & 0.49 & $<0.0001$ & 0.47 & $<0.0001$ \\
\hline $\mathrm{BMI}, \mathrm{kg} / \mathrm{m}^{2}$ & 0.13 & 0.08 & 0.02 & 0.80 \\
\hline $\mathrm{FEV}_{1}, \mathrm{~L}$ & -0.41 & $<0.0001$ & -0.25 & $<0.001$ \\
\hline $\mathrm{FEV}_{1}, \%$ predicted & -0.42 & $<0.0001$ & -0.17 & 0.02 \\
\hline $\mathrm{FEV}_{1} / \mathrm{FVC}$ & -0.34 & $<0.0001$ & -0.23 & 0.001 \\
\hline FVC, L & -0.31 & $<0.0001$ & -0.16 & 0.03 \\
\hline FVC, \% predicted & -0.40 & $<0.0001$ & -0.07 & 0.33 \\
\hline Reversibility, $\Delta \mathrm{FEV}_{1} \%$ predicted & -0.20 & 0.01 & -0.19 & 0.01 \\
\hline ICS, $\mu \mathrm{g} / \mathrm{d}$ & 0.12 & 0.11 & -0.05 & 0.51 \\
\hline $\begin{array}{l}\text { St. George's Respiratory Questionnaire } \\
\text { score }\end{array}$ & 0.21 & 0.01 & 0.04 & 0.58 \\
\hline Asthma Control Questionnaire score & 0.22 & 0.01 & 0.03 & 0.74 \\
\hline Periostin, ng/ml & 0.12 & 0.11 & -0.04 & 0.59 \\
\hline Smoking, pack-years & 0.32 & $<0.001$ & 0.34 & $<0.001$ \\
\hline $\mathrm{F}_{\mathrm{NO}}, \mathrm{ppb}$ & -0.05 & 0.68 & -0.08 & 0.42 \\
\hline $\mathrm{CRP}, \mathrm{mg} / \mathrm{L}$ & 0.17 & 0.04 & 0.08 & 0.33 \\
\hline $\mathrm{lgE}, \mathrm{kU} / \mathrm{L}$ & -0.05 & 0.51 & -0.10 & 0.16 \\
\hline Sputum eosinophils, \% & -0.15 & 0.16 & 0.05 & 0.62 \\
\hline Sputum neutrophils, \% & 0.16 & 0.14 & 0.15 & 0.13 \\
\hline Sputum macrophages, \% & -0.15 & 0.11 & -0.16 & 0.06 \\
\hline Blood eosinophils, $10^{9} / \mathrm{L}$ & -0.15 & 0.05 & -0.05 & 0.54 \\
\hline Blood neutrophils, $10^{9} / \mathrm{L}$ & 0.08 & 0.28 & 0.11 & 0.16 \\
\hline
\end{tabular}

Definition of abbreviations: BIOAIR = Longitudinal Assessment of Clinical Course and Biomarkers in Severe Chronic Airway Disease; BMI = body mass index; $\mathrm{CRP}=\mathrm{C}$-reactive protein; $\mathrm{F}_{\mathrm{E}}=$ fraction of exhaled nitric oxide; ICS = inhaled corticosteroids.

analyzed separately (Tables E9-E11), we found that the factors affecting chitotriosidase activity were age and genotype. A relationship with pack-years of smoking was observed only in patients with mild asthma, in whom it should be noted that the number of patients with a positive smoking history was also relatively low (15 of 76).

\section{Effect of Allergen Challenge on YKL-40 Levels}

The effects of high-dose and repeated low-dose allergen challenges on plasma and sputum YKL-40 levels were examined in patients with mild atopic asthma (Figure 4). Plasma YKL-40 was not affected by either high-dose allergen challenge or repeated low-dose allergen challenge, although both challenges resulted in significant physiological responses (i.e., reductions in $\mathrm{FEV}_{1}$ and increased responsiveness toward inhaled methacholine) $(18,19)$. Sputum YKL-40 levels were significantly higher following high-dose allergen challenge (before challenge, 68 [48-96] ng/g sputum; after challenge, 113
[69-258] ng/g sputum; $\mathrm{n}=15 ; P=0.007)$, but they were not affected by repeated low-dose allergen challenge. Sputum YKL-40 levels correlated with number of sputum neutrophils in both studies $(r=0.5 ; P<0.05)$.

\section{Discussion}

The main findings of the present study are that serum YKL-40 levels and chitotriosidase activity are elevated in patients with asthma and in patients with COPD compared with healthy control subjects. Both YKL-40 and chitotriosidase were higher in subjects with COPD than in patients with mild to moderate asthma or those with severe asthma, and the increased levels correlated with reduced lung function and were relatively steroid insensitive. We demonstrate that genetic variability and age strongly affect both YKL-40 and chitotriosidase activity but that the increased levels compared with healthy control subjects mostly persisted after adjustment for these factors. Acute changes in airway inflammation caused by allergen exposure or naturally occurring exacerbations were without effect on the circulating chitinases measured, and the variability of serum YKL-40 and chitotriosidase activity over time was relatively low. Taken together, these findings confirm that the chitinases represent a distinct class of biomarkers of severe airway disease and provide important information regarding their use as such.

Serum YKL-40 levels and chitotriosidase activity have not previously been examined in parallel in patients with COPD and patients with asthma. The finding of increased serum YKL-40 in patients with asthma confirms previous observations $(7,8,24,25)$. The higher levels in patients with severe asthma than in patients with mild asthma, along with the correlation between YKL-40 and reduced lung function, strengthen the association of serum YKL-40 with disease severity $(7,8)$. The exact biological role of YKL-40 remains unclear, but it consistently correlates with airway obstruction in studies of patients with asthma $(7,8,24)$. YKL-40 associates with measures of airway remodeling, such as bronchial wall thickness and subepithelial

Figure 2. (Continued). duplication in exon 10 of CHIT1 rs3831317 (wild type), those heterozygous for the 24-bp duplication, and those homozygous for the 24-bp duplication. Information regarding CHIT1 genotype and chitotriosidase activity were available from 64 healthy control subjects and 51 patients with mild to moderate asthma, 67 with severe asthma, and 44 with COPD. The results are presented as individual data points with median bars. ${ }^{\star} P<0.05$, ${ }^{\star \star} P<0.01,{ }^{\star \star \star} P<0.001$. 
Table 4. YKL-40 Levels and Chitotriosidase Activity in Th2-Low and Th2-High Patients with Asthma

\section{Th2-Low}

Th2-High

$36.5(25.5-55.6)(n=46)$

$36.9(21.9-53.4)(n=43)$

$84.7(56.5-122.8)(n=47)$
$P$ Value

0.49

0.19

Chitotriosidase activity, $\mathrm{nmol} / \mathrm{ml} / \mathrm{h}$

Definition of abbreviation: Th2 = T-helper cell type 2 .

Asthma patients were grouped according to having both serum periostin levels and blood eosinophil numbers above (Th2-high) or below (Th2-low) the group median (median eosinophil count, $0.25 \times 10^{9} / \mathrm{L}$; median periostin level, $84 \mathrm{ng} / \mathrm{ml}$ ). Results are presented as median (interquartile range).

fibrosis $(7,8)$, which is in line with reports that YKL-40 increases the proliferation of bronchial smooth muscle cells $(26,27)$ and is involved in fibrotic lung diseases (28). Also of relevance to a role in airway remodeling is the discovery that a high serum YKL-40 level is associated with a greater decline in lung function over time (29). The increased YKL-40 levels in patients with COPD compared with patients with asthma may therefore reflect a greater degree of airway remodeling.

It is widely recognized that asthma is a heterogeneous disorder of multiple phenotypes characterized by differing clinical characteristics and underlying pathobiology. Patients with Th2-driven asthma have been described as being more atopic and more sensitive to corticosteroid therapy and as having more airway eosinophils and a greater degree of bronchial hyperresponsiveness (30). Blood eosinophils, $\mathrm{FE}_{\mathrm{NO}}$, and serum periostin levels have been described as potential biomarkers of Th2-type airway

inflammation (30). In the present study, we did not observe any relationships between either YKL-40 or chitotriosidase with atopic status, response to corticosteroid therapy, blood eosinophil numbers, or serum periostin levels. Dividing patients into Th2-high and Th2-low groups based on having both high blood eosinophil and high periostin levels did not reveal any differences in chitinase levels.

In accordance with our findings, Jia and colleagues showed that whereas periostin may be the most sensitive and specific indicator of airway eosinophilia, there were no correlations between YKL-40 with periostin, eosinophils (in blood, sputum, or tissue), or $\mathrm{FE}_{\mathrm{NO}}$ (31). Regarding atopy, the reported findings are variable. On one hand, Chupp and colleagues (7) and Ober and coworkers (12) reported no associations between YKL-40 with atopy or IgE. On the other hand, Tang and colleagues (24) found higher circulating YKL-40 levels in Chinese patients with higher IgE levels, and Specjalski and coworkers (32) made the same observation in patients with atopic versus nonatopic asthma. In the present study, we also observed the highest levels of YKL-40 and chitotriosidase in patients with COPD, further suggesting that the chitinases are not Th2-specific markers of airway disease. Interestingly, a weak association with increased BMI was observed, which has also been described previously (32). In contrast to our findings, initial studies in mice did suggest an involvement in Th2type processes, as the expression of chitinase proteins (AMCase, Ym1, and $\mathrm{Ym} 2$ ) is dependent on IL-13 $(3,33,34)$ and mice lacking Brp39 (YKL-40) have defective IL-13-induced inflammation (35).

Chitotriosidase activity was significantly elevated in patients with mild to moderate asthma compared with healthy control subjects, but not in patients with severe asthma, following adjustment for age, sex, and genotype. Published reports regarding chitotriosidase activity in asthma are few and varied, with differences based on the matrix studied, the severity of patients' disease, and/or patients' current medications. Studies have shown that, compared with healthy control subjects, there may be reduced chitotriosidase activity in bronchoalveolar lavage (BAL) fluid from patients with mild asthma not being treated with steroids (4), no difference in serum from patients with asthma (36), and increased levels in the serum of patients with asthma with or without allergies (6). The lack of association with disease severity, alongside conflicting previous findings, suggests that the involvement of chitotriosidase in asthma is less clear than that of YKL-40.

The increased YKL-40 and chitotriosidase seen in patients with COPD is in accordance with previous observations. Increased BAL chitotriosidase activity has been found in smokers $(4,5)$, and elevated circulating YKL-40 has been found in patients with COPD compared with control subjects, in whom levels may relate to smoking history $(37,38)$. In the present study, no differences were observed between current smokers and ex-smokers, suggesting that current smoke exposure per $s e$ is not responsible for increased chitinase levels. However, a significant relationship between chitotriosidase activity and packyears of smoking was observed in the multiple regression analyses, suggesting that the degree of airway damage may affect
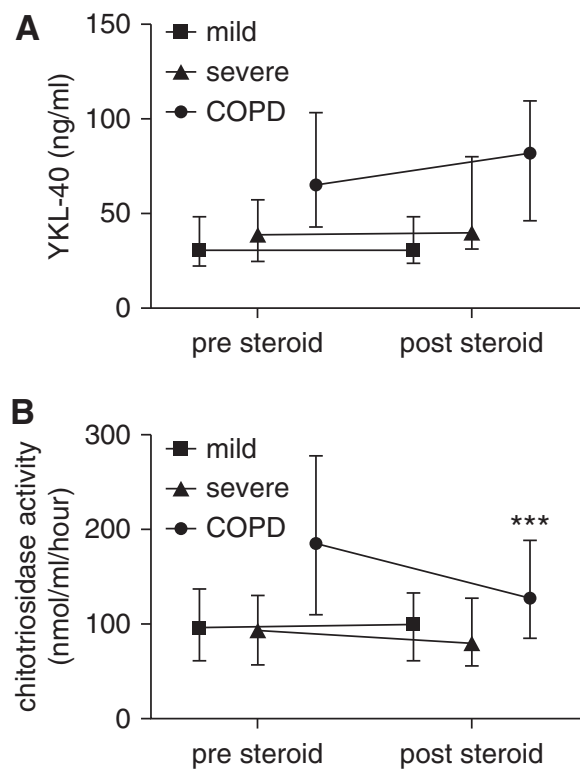

Figure 3. Effect of oral corticosteroid treatment on serum chitotriosidase activity and $\mathrm{YKL}-40$ levels. (A) Serum YKL-40 levels and $(B)$ chitotriosidase activity were measured before and after 2 weeks of treatment with oral prednisolone. The results are presented as median values (with interquartile range) for patients with chronic obstructive pulmonary disease (COPD), severe asthma, and mild to moderate asthma. Paired comparisons were possible for 55 (YKL-40) and 53 (chitotriosidase) patients with mild to moderate asthma, 67 (YKL-40) and 66 (chitotriosidase) patients with severe asthma, and 38 patients with COPD. ${ }^{\star \star *} P<0.001$ compared with presteroid values. 
Table 5. Biomarker Stability in the BIOAIR Study

\section{Mild to Moderate Asthma Severe Asthma COPD}

Chitotriosidase activity
YKL-40
FE $E_{\text {NO }}$
Sputum eosinophil percentage

19
32
45
95

$\begin{array}{rr}16 & 17 \\ 36 & 38 \\ 46 & 52 \\ 91 & 106\end{array}$

Definition of abbreviations: BIOAIR = Longitudinal Assessment of Clinical Course and Biomarkers in Severe Chronic Airway Disease; $\mathrm{COPD}=$ chronic obstructive pulmonary disease; $\mathrm{FE}_{\mathrm{NO}}=$ fraction of exhaled nitric oxide.

Data represent average between-visit coefficient of variation (as a percentage) of up to six repeat visits. chitotriosidase activity. There may be involvement of airway neutrophils and macrophages, as these were more abundant in COPD sputum compared with asthma sputum. Both neutrophils and macrophages are known sources of YKL-40 and chitotriosidase (39-41), although no obvious relationships were observed between airway neutrophils and macrophages and either YKL-40 or chitotriosidase in BIOAIR study patients.

We and others have demonstrated that serum levels of both YKL-40 and chitotriosidase increase with age $(42,43)$. The patient groups in the BIOAIR study were not age matched, but significant between-group differences remained following statistical adjustment for age, suggesting that age alone is not responsible for any of the observed increases in chitinase levels.

YKL-40 and chitotriosidase levels were both strongly affected by variations in the CHI3L1 and CHIT1 genes, respectively. Genetic variants in the CHI3L1 gene have been associated with asthma and related phenotypes (12, 44-46). Ober and colleagues (12) observed a relationship between one particular CHI3L1 polymorphism $(-131 \mathrm{C}>\mathrm{G}$ rs4950928), circulating YKL-40 levels, and asthma. We confirm that the rs4950928 CC genotype was associated with greater levels of circulating YKL-40; in contrast to Ober and colleagues, however, we did not observe any associations with markers of asthma
Table 6. Multiple Regression Analyses in BIOAIR Patients

\begin{tabular}{|c|c|c|c|}
\hline & $\beta(95 \% \mathrm{Cl})$ & $P$ Value & Adjusted $R^{2}$ \\
\hline \multicolumn{4}{|l|}{$Y K L-40, n=140$} \\
\hline Age & $0.017(0.009-0.025)$ & $<0.001$ & \\
\hline FVC, \% predicted, spline 1 & $-0.032(-0.044$ to -0.021$)$ & $<0.001$ & \\
\hline FVC, \% predicted, spline 2 & $0.021(0.010-0.032)$ & $<0.001$ & \\
\hline CHI3L 1 rs 4950928, CC vs. CG & $-0.457(-0.668$ to -0.246$)$ & $<0.001$ & \\
\hline CHI3L 1 rs4950928, CC vs. GG & $-0.959(-1.360$ to -0.558$)$ & $<0.001$ & \\
\hline Sex & $-0.331(-0.541$ to -0.120$)$ & 0.002 & \\
\hline Smoking pack-years & $-0.003(-0.012$ to 0.005$)$ & 0.419 & \\
\hline Group, MA vs. SA & $0.046(-0.211$ to 0.303$)$ & 0.725 & \\
\hline Group, MA vs. COPD & $0.136(-0.330$ to 0.601$)$ & 0.566 & \\
\hline Combined model & & & 0.512 \\
\hline \multicolumn{4}{|l|}{ Chitotriosidase, $n=152$} \\
\hline Age & $0.019(0.012-0.025)$ & $<0.001$ & \\
\hline CHIT1 rs3831317, WT vs. HET & $-0.746(-0.925$ to -0.567$)$ & $<0.001$ & \\
\hline Pack-years, spline 1 & $0.042(0.015-0.068)$ & 0.002 & \\
\hline Pack-years, spline 2 & $-0.066(-0.111$ to -0.021$)$ & 0.005 & \\
\hline Group, MA vs. COPD & $-0.569(-1.080$ to -0.057$)$ & 0.030 & \\
\hline Group, MA vs. SA & $-0.147(-0.359$ to 0.065$)$ & 0.174 & \\
\hline Sex & $-0.084(-0.260$ to 0.092$)$ & 0.347 & \\
\hline FVC, \% predicted & $0.002(-0.002$ to 0.007$)$ & 0.301 & \\
\hline Combined model & & & 0.473 \\
\hline
\end{tabular}

Definition of abbreviations: BIOAIR = Longitudinal Assessment of Clinical Course and Biomarkers in Severe Chronic Airway Disease; $\mathrm{Cl}=$ confidence interval; COPD = chronic obstructive pulmonary disease; $\mathrm{HET}=$ heterozygous for 24-bp duplication at rs3831317; $\mathrm{MA}=$ mild to moderate asthma; SA = severe asthma; WT = wild type lacking 24-bp duplication at rs3831317. severity, which has also been the case in other recent investigations (46). As DNA methylation can affect transcription factor binding, we investigated the effect of DNA methylation at three sites located in the $C H I 3 L 1$ promoter region near rs4950928 because this single-nucleotide polymorphism affects MYC and MAX binding (12). However, no clear trends were observed between DNA methylation in this region and circulating YKL-40 levels (Figure E1 and Table E3). The CHIT1 24-bp duplication (rs3831317) results in a nonfunctional protein lacking enzymatic activity (13). This genetic variant shows no association with asthma and atopy $(47,48)$, and in the present study no differences in the frequencies of the CHIT1 rs3831317 variants were observed in the different disease groups.

The BIOAIR study included a 2-week, placebo-controlled steroid intervention with oral prednisolone. In patients with asthma, steroid treatment did not reduce serum YKL-40 or chitotriosidase activity. There was a reduction in serum chitotriosidase activity, but not of YKL-40, after steroid treatment in patients with COPD, those who were oldest, and those who had the highest levels of chitotriosidase activity. It should be noted, however, that subjects in the BIOAIR study used inhaled corticosteroids. That could potentially have affected basal chitinase levels, as Lai and colleagues recently showed that serum YKL-40 was reduced following 8 weeks of inhaled corticosteroid treatment (49). Nevertheless, as we and others have shown, patients taking the highest doses of ICS are also those with the highest levels of YKL-40, suggesting that YKL-40 release is relatively refractory to steroid treatment $(7,49)$. One may speculate that the reason why chitinase levels are highest in patients with the most severe disease and taking the highest levels of corticosteroids is that corticosteroids are able to alternatively activate macrophages, a cell type known to release mediators involved in tissue repair (50).

To investigate the repeatability of chitinase measurements, up to six serum samples were collected from the same patients over a 1-year period. The mean coefficients of variation were $16-19 \%$ for chitotriosidase and $32-38 \%$ for YKL- 40 . In comparison with other biomarkers measured at the same time points, such as $\mathrm{FE}_{\mathrm{NO}}$ (coefficient of variation, 45-56\%) and sputum eosinophil percentage (coefficient 
Table 7. Variable Importance of Multiple Regression Analyses in BIOAIR Patients

\begin{tabular}{lcc}
\hline Variables & Conditional importance & Unadjusted $\boldsymbol{R}^{\mathbf{2}}$ \\
YKL-40 & & \\
FVC, \% predicted & 0.12362347 & 0.543417 \\
CHI3L1 rs4950928 genotype & 0.12105902 & 0.543417 \\
Age & 0.05651369 & 0.543417 \\
Sex & 0.03374412 & 0.543417 \\
Smoking pack-years & 0.00231065 & 0.543417 \\
Group & 0.00118992 & 0.543417 \\
Chitotriosidase & & \\
CHIT1 rs3831317 genotype & 0.23784618 & 0.5007306 \\
Age & 0.10398267 & 0.5007306 \\
Smoking pack-years & 0.03569944 & 0.5007306 \\
Group & 0.01845461 & 0.5007306 \\
FVC, \% predicted & 0.00375439 & 0.5007306 \\
Sex & 0.00310467 & 0.5007306 \\
\hline
\end{tabular}

Definition of abbreviation: BIOAIR = Longitudinal Assessment of Clinical Course and Biomarkers in Severe Chronic Airway Disease.

of variation, 91-95\%), both chitotriosidase and YKL-40 were relatively stable.

Naturally occurring exacerbations, most commonly caused by viral infections, in patients with severe asthma and patients with COPD were without effect on the levels of the chitinases measured, suggesting that they do not reflect acute changes in airway inflammation.
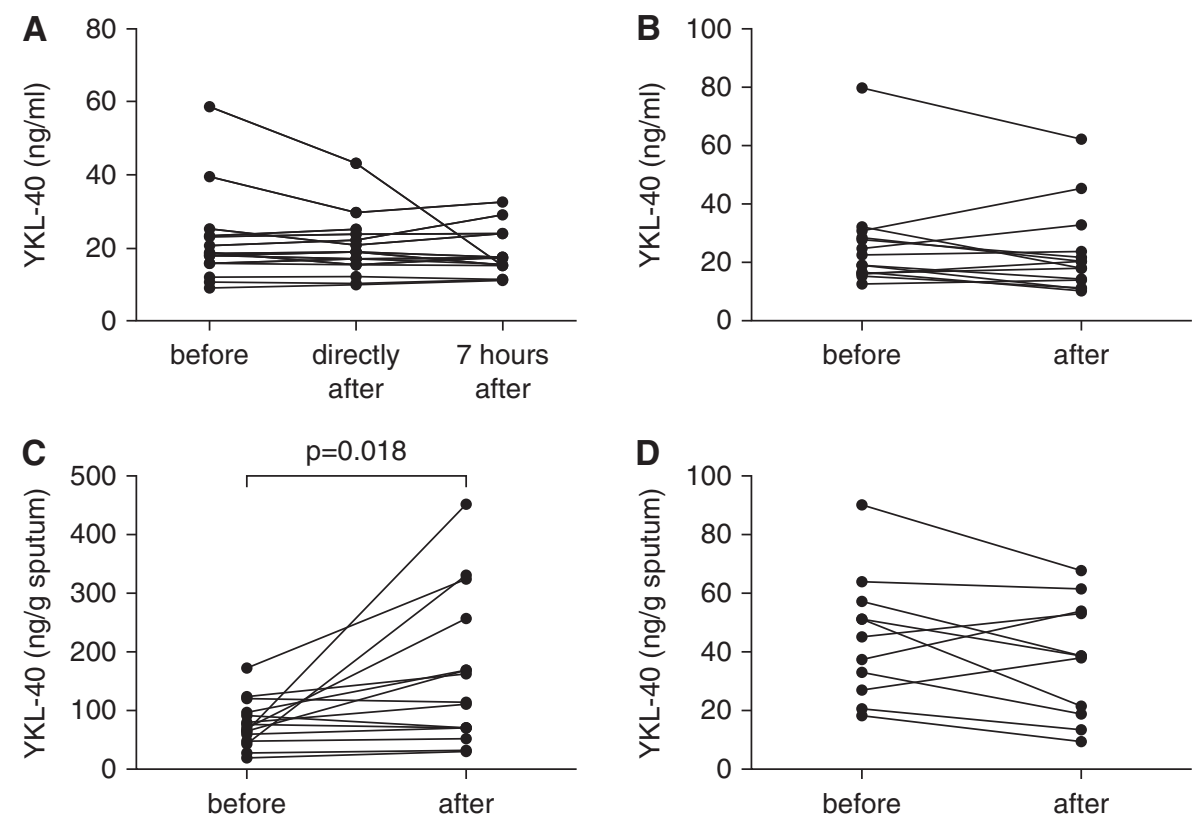

Figure 4. Plasma and sputum levels of YKL-40 following high-dose and repeated low-dose allergen challenges. Plasma levels of YKL-40 were measured $(A)$ before, directly after, and 7 hours after highdose allergen challenge $(n=16)$ and $(B)$ before and after a 7 -day repeated low-dose allergen challenge $(n=14)$. No significant differences were observed. Sputum supernatant levels of $Y K L-40$ were measured $(C)$ before and 6 hours after high-dose allergen challenge $(n=15)$ and $(D)$ before and after a 7 -day repeated low-dose allergen challenge $(n=11)$. The results are expressed as nanograms of YKL-40 per gram of processed sputum. High-dose allergen challenge significantly increased sputum YKL-40 ( $P=0.018)$, but low-dose allergen challenge was without effect. and colleagues found that BAL fluid YKL-40 levels were increased 48 hours after in vivo segmental high-dose allergen challenge (52). Taken together, these data seem to show that sputum (and BAL) may reflect a local release of YKL-40 during allergen-induced inflammation that is not reflected in the blood. A single high dose of allergen may be considered a greater challenge for the airways than repeated low doses, and, as the latter is considered a more realistic model of natural allergen exposure, YKL-40 levels may remain relatively stable during such exposures in everyday life. In both studies, sputum YKL-40 correlated with neutrophil numbers, confirming previous reports of the cellular origin of YKL-40 (41).

As the BIOAIR study was designed to compare severe asthma and COPD with mild asthma, the study cohort lacks an internal healthy control group, which is a limitation. To compare chitinase levels with those in healthy subjects, we used a previously described control group (17). However, clinical characteristics of relevance to respiratory disease were not available for these control subjects, thus preventing their inclusion in multiple regression analyses. Nevertheless, performing such analyses for the groups with respiratory disease only was able to further highlight the importance of age, genotype, lung function, and sex on YKL-40 levels and similarly the effects of age, genotype, and smoking history on chitotriosidase activity.

In conclusion, we demonstrate that YKL40 and chitotriosidase are relatively steroidinsensitive biomarkers that are distinctly elevated in well-characterized patients with asthma and patients with COPD. Taking into account age and genetic variability, the chitinases qualify for measurement as part of new biomarker panels for the assessment of severe, chronic lung inflammation rather than acute lung inflammation. Furthermore, it will be of interest in future longitudinal studies to test the prognostic value of monitoring chitinases as biomarkers of decline in lung function (29), be it in patients with asthma, COPD, fibrosis, or infections or in pediatric conditions such as bronchopulmonary dysplasia.

Author disclosures are available with the text of this article at www.atsjournals.org.

\section{Acknowledgment: BIOAIR collaborators:}

Mina Gaga, M.D., Ph.D., University of Athens, Athens, Greece; Nikos M. Siafakas, M.D. Ph.D., University of Crete, Rethymno, Greece; Alberto Papi, M.D., University of Ferrara, 
Ferrara, Italy; Leonardo M. Fabbri, M.D., University of Modena, Modena, Italy; Guy Joos, M.D., Ph.D., University of Gent, Gent, Belgium Guy Brusselle, M.D., Ph.D., University of Gent, Gent, Belgium; Klaus F. Rabe, M.D., Ph.D. Leiden University Medical Centre, Leiden, the Netherlands, and Pulmonary Research Institute at Lung Clinic Grosshansdorf, Grosshansdorf, Germany; Frank Kanniess, M.D., Pulmonary Research Institute at Lung Clinic

Grosshansdorf, Grosshansdorf, Germany;
Pieter Hiemstra, Ph.D., University of Leiden, Leiden, the Netherlands; Sebastian L. Johnston, M.D., Ph.D., Imperial College of Science and Technology, London, United Kingdom; Pascal Chanez, M.D., Ph.D., University of Marseille, Marseille, France; Isabelle Vachier, M.D., Ph.D., University of Montpellier, Montpellier, France; Mark Gjomarkaj, M.D., Italian Research Council, Palermo, Italy; Peter J. Sterk, M.D., Ph.D., University of Amsterdam, Amsterdam, the
Netherlands; Peter H. Howarth, M.D., Ph.D., University of Southampton, Southampton, United Kingdom; Ewa NizankowskaMogilnicka, M.D., Ph.D., The Jagellonian University, Krakow, Poland; Roelinde Middelveld, Ph.D., Karolinska Institutet, Stockholm, Sweden; Stephen T. Holgate, M.D., D.Sc., University of Southampton,

Southampton, United Kingdom; and Susan Wilson, Ph.D., University of Southampton, Southampton, United Kingdom.

\section{References}

1. Bussink AP, Speijer D, Aerts JM, Boot RG. Evolution of mammalian chitinase(-like) members of family 18 glycosyl hydrolases. Genetics 2007;177:959-970.

2. Lee CG, Da Silva CA, Dela Cruz CS, Ahangari F, Ma B, Kang MJ, $\mathrm{He} C H$, Takyar S, Elias JA. Role of chitin and chitinase/chitinase-like proteins in inflammation, tissue remodeling, and injury. Annu Rev Physiol 2011; 73:479-501.

3. Zhu Z, Zheng T, Homer RJ, Kim YK, Chen NY, Cohn L, Hamid Q, Elias JA. Acidic mammalian chitinase in asthmatic Th2 inflammation and IL-13 pathway activation. Science 2004;304:1678-1682.

4. Seibold MA, Donnelly S, Solon M, Innes A, Woodruff PG, Boot RG, Burchard EG, Fahy JV. Chitotriosidase is the primary active chitinase in the human lung and is modulated by genotype and smoking habit. J Allergy Clin Immunol 2008;122:944-950.e3.

5. Létuvé S, Kozhich A, Humbles A, Brewah Y, Dombret MC, Grandsaigne M, Adle H, Kolbeck R, Aubier M, Coyle AJ, et al. Lung chitinolytic activity and chitotriosidase are elevated in chronic obstructive pulmonary disease and contribute to lung inflammation. Am J Patho 2010;176:638-649.

6. Bargagli E, Olivieri C, Margollicci M, Bennett D, Luddi A, Perrone M, Maggiorelli C, Prasse A, Rottoli P. Serum chitotriosidase levels in patients with allergic and non-allergic asthma. Respiration 2010;79: 437-438.

7. Chupp GL, Lee CG, Jarjour N, Shim YM, Holm CT, He S, Dziura JD, Reed J, Coyle AJ, Kiener P, et al. A chitinase-like protein in the lung and circulation of patients with severe asthma. N Engl J Med 2007; 357:2016-2027.

8. Konradsen JR, James A, Nordlund B, Reinius LE, Söderhäll C, Melén E, Wheelock AM, Lödrup Carlsen KC, Lidegran M, Verhoek M, et al. The chitinase-like protein YKL-40: a possible biomarker of inflammation and airway remodeling in severe pediatric asthma. J Allergy Clin Immunol 2013;132:328-335.e5.

9. Kupczyk M, Haque S, Middelveld RJ, Dahlén B, Dahlén SE; BIOAIR Investigators. Phenotypic predictors of response to oral glucocorticosteroids in severe asthma. Respir Med 2013;107:1521-1530.

10. Kupczyk M, Haque S, Sterk PJ, Niżankowska-Mogilnicka E, Papi A, Bel EH, Chanez P, Dahlén B, Gaga M, Gjomarkaj M, et al.; BIOAIR investigators. Detection of exacerbations in asthma based on electronic diary data: results from the 1-year prospective BIOAIR study. Thorax 2013;68:611-618.

11. Kupczyk M, ten Brinke A, Sterk PJ, Bel EH, Papi A, Chanez $P$, Nizankowska-Mogilnicka E, Gjomarkaj M, Gaga M, Brusselle G, et al.; BIOAIR investigators. Frequent exacerbators - a distinct phenotype of severe asthma. Clin Exp Allergy 2014;44:212-221.

12. Ober C, Tan Z, Sun Y, Possick JD, Pan L, Nicolae R, Radford S, Parry RR, Heinzmann A, Deichmann KA, et al. Effect of variation in CHI3L1 on serum YKL-40 level, risk of asthma, and lung function. $N$ Engl $J$ Med 2008;358:1682-1691.

13. Boot RG, Renkema GH, Verhoek M, Strijland A, Bliek J, de Meulemeester TM, Mannens MM, Aerts JM. The human chitotriosidase gene: nature of inherited enzyme deficiency. $J$ Biol Chem 1998;273:25680-25685.

14. James A, Johansson L, Boot R, Kupczyk M, Middelveld R, Weersink E, Bel E, Söderhäll C, Dahlén B, Kere J, et al.; on behalf of the BIOAIR study group. Airway inflammation in COPD and asthma is associated with elevated serum chitotriosidase activity in a genotype dependent manner [abstract]. Am J Respir Crit Care Med 2010;181:A1330.

15. James A, Boot R, Weersink E, Kupczyk M, Middelveld R, Bel E, Dahlén B, Johansson L, Aerts J, Dahlén SE. Oral corticosteroid treatment reduces serum chitotriosidase activity in patients with COPD. Presented at the 2010 European Respiratory Society Annual Meeting. September 19, 2010, Barcelona, Spain. Poster P1321, p. 237s.

16. James A, Gomes A, Daham K, Ono J, Ohta S, Dahlen B, Izuhara K, Dahlen SE. Effect of allergen challenge on two novel biomarkers of airway inflammation, periostin and YKL-40, in atopic asthmatic patients [abstract]. Am J Respir Crit Care Med 2014;189:A4244.

17. Vedder AC, Cox-Brinkman J, Hollak CE, Linthorst GE, Groener JE, Helmond MT, Scheij S, Aerts JM. Plasma chitotriosidase in male Fabry patients: a marker for monitoring lipid-laden macrophages and their correction by enzyme replacement therapy. Mol Genet Metab 2006;89:239-244.

18. Daham K, James A, Balgoma D, Kupczyk M, Billing B, Lindeberg A, Henriksson E, FitzGerald GA, Wheelock CE, Dahlén SE, et al. Effects of selective COX-2 inhibition on allergen-induced bronchoconstriction and airway inflammation in asthma. J Allergy Clin Immunol 2014;134:306-313.

19. Dahlén B, Lantz AS, Ihre E, Skedinger M, Henriksson E, Jörgensen L, Ekström T, Dahlén SE, Larsson K. Effect of formoterol with or without budesonide in repeated low-dose allergen challenge. Eur Respir J 2009;33:747-753

20. Okamoto M, Hoshino T, Kitasato Y, Sakazaki Y, Kawayama T, Fujimoto $\mathrm{K}$, Ohshima K, Shiraishi H, Uchida M, Ono J, et al. Periostin, a matrix protein, is a novel biomarker for idiopathic interstitial pneumonias. Eur Respir J 2011;37:1119-1127.

21. Aguilera B, Ghauharali-van der Vlugt K, Helmond MT, Out JM, DonkerKoopman WE, Groener JE, Boot RG, Renkema GH, van der Marel $\mathrm{GA}$, van Boom JH, et al. Transglycosidase activity of chitotriosidase: improved enzymatic assay for the human macrophage chitinase. J Biol Chem 2003;278:40911-40916.

22. Schoonhoven A, Rudensky B, Elstein D, Zimran A, Hollak CE, Groener $\mathrm{JE}$, Aerts JM. Monitoring of Gaucher patients with a novel chitotriosidase assay. Clin Chim Acta 2007:381:136-139.

23. Durrleman S, Simon R. Flexible regression models with cubic splines. Stat Med 1989;8:551-561.

24. Tang H, Fang Z, Sun Y, Li B, Shi Z, Chen J, Zhang T, Xiu Q. YKL-40 in asthmatic patients, and its correlations with exacerbation, eosinophils and immunoglobulin E. Eur Respir J 2010;35:757-760.

25. Specjalski K, Jassem E. YKL-40 protein is a marker of asthma. J Asthma 2011;48:767-772.

26. Bara I, Ozier A, Girodet PO, Carvalho G, Cattiaux J, Begueret H, Thumerel M, Ousova O, Kolbeck R, Coyle AJ, et al. Role of YKL-40 in bronchial smooth muscle remodeling in asthma. Am J Respir Crit Care Med 2012;185:715-722.

27. Tang $H$, Sun $Y$, Shi Z, Huang $H$, Fang Z, Chen J, Xiu Q, Li B. YKL-40 induces IL-8 expression from bronchial epithelium via MAPK (JNK and ERK) and NF-кB pathways, causing bronchial smooth muscle proliferation and migration. $J$ Immunol 2013;190:438-446.

28. Furuhashi K, Suda T, Nakamura $Y$, Inui N, Hashimoto D, Miwa $S$, Hayakawa $\mathrm{H}$, Kusagaya $\mathrm{H}$, Nakano $\mathrm{Y}$, Nakamura $\mathrm{H}$, et al. Increased expression of $\mathrm{YKL}-40$, a chitinase-like protein, in serum and lung of patients with idiopathic pulmonary fibrosis. Respir Med 2010;104: 1204-1210. 
29. Guerra S, Halonen M, Sherrill DL, Venker C, Spangenberg A, Carsin AE, Tarès L, Lavi I, Barreiro E, Martínez-Moratalla J, et al. The relation of circulating YKL-40 to levels and decline of lung function in adult life. Respir Med 2013;107:1923-1930.

30. Fajt ML, Wenzel SE. Asthma phenotypes and the use of biologic medications in asthma and allergic disease: the next steps toward personalized care. J Allergy Clin Immunol 2015;135:299-310, quiz 311.

31. Jia G, Erickson RW, Choy DF, Mosesova S, Wu LC, Solberg OD, Shikotra A, Carter R, Audusseau S, Hamid Q, et al.; Bronchoscopic Exploratory Research Study of Biomarkers in Corticosteroid-refractory Asthma (BOBCAT) Study Group. Periostin is a systemic biomarker of eosinophilic airway inflammation in asthmatic patients. J Allergy Clin Immunol 2012;130:647-654.e10.

32. Specjalski K, Chełmińska M, Jassem E. YKL-40 protein correlates with the phenotype of asthma. Lung 2015;193:189-194.

33. Webb DC, McKenzie AN, Foster PS. Expression of the Ym2 lectinbinding protein is dependent on interleukin (IL)-4 and IL-13 signal transduction: identification of a novel allergy-associated protein. J Biol Chem 2001;276:41969-41976.

34. Welch JS, Escoubet-Lozach L, Sykes DB, Liddiard K, Greaves DR, Glass $C K$. $T_{H} 2$ cytokines and allergic challenge induce $Y m 1$ expression in macrophages by a STAT6-dependent mechanism. $J$ Biol Chem 2002;277:42821-42829.

35. Lee CG, Hartl D, Lee GR, Koller B, Matsuura H, Da Silva CA, Sohn MH, Cohn L, Homer RJ, Kozhich AA, et al. Role of breast regression protein 39 (BRP-39)/chitinase 3-like-1 in Th2 and IL-13-induced tissue responses and apoptosis. J Exp Med 2009;206:1149-1166.

36. Tercelj M, Salobir B, Simcic S, Wraber B, Zupancic M, Rylander R. Chitotriosidase activity in sarcoidosis and some other pulmonary diseases. Scand J Clin Lab Invest 2009;69:575-578.

37. Matsuura H, Hartl D, Kang MJ, Dela Cruz CS, Koller B, Chupp GL, Homer RJ, Zhou Y, Cho WK, Elias JA, et al. Role of breast regression protein-39 in the pathogenesis of cigarette smoke-induced inflammation and emphysema. Am J Respir Cell Mol Biol 2011;44: 777-786.

38. Holmgaard DB, Mygind LH, Titlestad IL, Madsen H, Pedersen SS, Johansen JS, Pedersen C. Plasma YKL-40 and all-cause mortality in patients with chronic obstructive pulmonary disease. BMC Pulm Med 2013;13:77.

39. van Eijk M, van Roomen $\mathrm{CP}$, Renkema GH, Bussink AP, Andrews $L$, Blommaart EF, Sugar A, Verhoeven AJ, Boot RG, Aerts JM. Characterization of human phagocyte-derived chitotriosidase, a component of innate immunity. Int Immunol 2005;17: 1505-1512.
40. Renkema GH, Boot RG, Au FL, Donker-Koopman WE, Strijland A, Muijsers AO, Hrebicek M, Aerts JM. Chitotriosidase, a chitinase, and the 39-kDa human cartilage glycoprotein, a chitin-binding lectin, are homologues of family 18 glycosyl hydrolases secreted by human macrophages. Eur J Biochem 1998;251:504-509.

41. Volck B, Price PA, Johansen JS, Sørensen O, Benfield TL, Nielsen HJ, Calafat J, Borregaard N. YKL-40, a mammalian member of the chitinase family, is a matrix protein of specific granules in human neutrophils. Proc Assoc Am Physicians 1998;110:351-360.

42. Bojesen SE, Johansen JS, Nordestgaard BG. Plasma YKL-40 levels in healthy subjects from the general population. Clin Chim Acta 2011; 412:709-712.

43. Kurt I, Abasli D, Cihan M, Serdar MA, Olgun A, Saruhan E, Erbil MK. Chitotriosidase levels in healthy elderly subjects. Ann NY Acad Sci 2007;1100:185-188.

44. Rathcke CN, Holmkvist J, Husmoen LL, Hansen T, Pedersen O, Vestergaard $\mathrm{H}$, Linneberg A. Association of polymorphisms of the CHI3L1 gene with asthma and atopy: a populations-based study of 6514 Danish adults. PLoS One 2009;4:e6106

45. Sohn MH, Lee JH, Kim KW, Kim SW, Lee SH, Kim KE, Kim KH, Lee CG, Elias JA, Lee MG. Genetic variation in the promoter region of chitinase 3-like 1 is associated with atopy. Am J Respir Crit Care Med 2009;179:449-456.

46. Gomez JL, Crisafi GM, Holm CT, Meyers DA, Hawkins GA, Bleecker ER, Jarjour N; Severe Asthma Research Program (SARP) Investigators; Cohn L, Chupp GL. Genetic variation in chitinase 3-like 1 (CHI3L1) contributes to asthma severity and airway expression of YKL-40. J Allergy Clin Immunol 2015;136:51-58.e10.

47. Bierbaum S, Superti-Furga A, Heinzmann A. Genetic polymorphisms of chitotriosidase in Caucasian children with bronchial asthma. Int $J$ Immunogenet 2006;33:201-204.

48. Wu AC, Lasky-Su J, Rogers CA, Klanderman BJ, Litonjua A. Polymorphisms of chitinases are not associated with asthma. J Allergy Clin Immunol 2010;125:754-757.e2.

49. Lai T, Chen M, Deng Z, Lü Y, Wu D, Li D, Wu B. YKL-40 is correlated with $\mathrm{FEV}_{1}$ and the asthma control test (ACT) in asthmatic patients: influence of treatment. BMC Pulm Med 2015;15:1.

50. Mosser DM. The many faces of macrophage activation. $J$ Leukoc Biol 2003;73:209-212.

51. Lee JH, Park KH, Park JW, Hong CS. YKL-40 in induced sputum after allergen bronchial provocation in atopic asthma. $J$ Investig Allergol Clin Immunol 2012;22:501-507.

52. Gavala ML, Kelly EA, Esnault S, Kukreja S, Evans MD, Bertics PJ, Chupp GL, Jarjour NN. Segmental allergen challenge enhances chitinase activity and levels of CCL18 in mild atopic asthma. Clin Exp Allergy 2013;43:187-197. 